\title{
High-fat feeding induces mobilization of vitamin C in obese prone rats
}

Tranberg, B.; Hellgren, L.I.; Lykkesfeldt, J.; Hansen, A.K.

\section{Published in:}

Research in Veterinary Science

Link to article, DOI:

10.1016/j.rvsc.2018.06.011

Publication date:

2018

Document Version

Peer reviewed version

Link back to DTU Orbit

Citation (APA):

Tranberg, B., Hellgren, L. I., Lykkesfeldt, J., \& Hansen, A. K. (2018). High-fat feeding induces mobilization of vitamin C in obese prone rats. Research in Veterinary Science, 119, 167-169.

https://doi.org/10.1016/j.rvsc.2018.06.011

\section{General rights}

Copyright and moral rights for the publications made accessible in the public portal are retained by the authors and/or other copyright owners and it is a condition of accessing publications that users recognise and abide by the legal requirements associated with these rights.

- Users may download and print one copy of any publication from the public portal for the purpose of private study or research.

- You may not further distribute the material or use it for any profit-making activity or commercial gain

- You may freely distribute the URL identifying the publication in the public portal

If you believe that this document breaches copyright please contact us providing details, and we will remove access to the work immediately and investigate your claim 


\section{Accepted Manuscript}

High-fat feeding induces mobilization of vitamin $\mathrm{C}$ in obese prone rats

B. Tranberg, L.I. Hellgren, J. Lykkesfeldt, A.K. Hansen

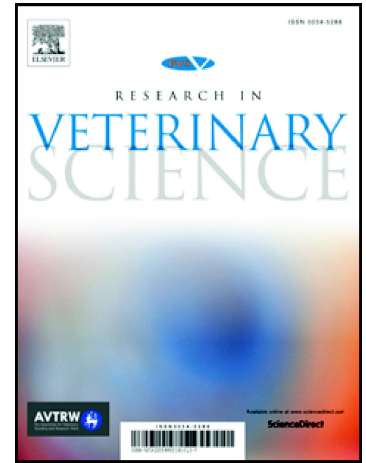

PII:

S0034-5288(18)30109-7

DOI:

doi:10.1016/j.rvsc.2018.06.011

Reference:

YRVSC 3594

To appear in:

Research in Veterinary Science

Received date:

7 February 2018

Revised date:

6 June 2018

Accepted date:

10 June 2018

Please cite this article as: B. Tranberg, L.I. Hellgren, J. Lykkesfeldt, A.K. Hansen, High-fat feeding induces mobilization of vitamin C in obese prone rats. Yrvsc (2017), doi:10.1016/j.rvsc.2018.06.011

This is a PDF file of an unedited manuscript that has been accepted for publication. As a service to our customers we are providing this early version of the manuscript. The manuscript will undergo copyediting, typesetting, and review of the resulting proof before it is published in its final form. Please note that during the production process errors may be discovered which could affect the content, and all legal disclaimers that apply to the journal pertain. 
High-fat Feeding Induces Mobilization of Vitamin C in Obese Prone Rats

B Tranberg ${ }^{1}$, L I Hellgren ${ }^{21}$, J Lykkesfeldt ${ }^{1}$, and A K Hansen ${ }^{1, *}$ akh@ sund.ku.dk

${ }^{1}$ Department of Veterinary and Animal Sciences, Faculty of Health and Medical Sciences, University of Copenhagen, Frederiksberg C, Denmark

${ }^{2}$ Department of Systems Biology, Center for Biological Sequence Analysis, Technical University of Denmark, Lyngby, Denmark

*Corresponding author.

Keywords:

Vitamin C; Obesity; High-fat Diet; Rat; Insulin Resistance

Abstract

In obesity and dyslipidemia, hydrolysis of triacylglycerol (TAG) into non-esterified fatty acids (NEFAs) may contribute to insulin resistance, and production of oxygenated, bioactive polyunsaturated fatty acids may increase oxidative stress. Here we show that after six weeks of high-fat feeding of obese prone rats $(\mathrm{Crl}: \mathrm{OP}(\mathrm{CD})$, vitamin $\mathrm{C}$ was increased both in liver $(\mathrm{P}<0.01)$ and plasma $(\mathrm{P}<0.001)$, while both TAG $(\mathrm{P}<0.01)$ and NEFA $(\mathrm{P}<0.001)$ were lower than in low-fat fed control rats. Hepatic vitamin $\mathrm{C}$ biosynthesis was similar between groups, indicating that a new steady state level was established with a higher vitamin $\mathrm{C}$ level adequate for supplying the systemic needs. Glucose and insulin sensitivity were unaffected at this stage. Eventually, the mobilization of vitamin $\mathrm{C}$ may be seen as a mechanism to protect the host against insulin resistance.

Diet-induced obese rodents are frequently used as models in obesity research. Obesity and dyslipidemia in humans are associated with increased risk of developing insulin resistance. As triacylglycerol (TAG) is hydrolysed, the increased plasma concentration

\footnotetext{
${ }^{1}$ Deceased June 62017
} 
of non-esterified fatty acids (NEFA) may contribute to insulin resistance (Boden, 2011). An altered production of oxygenated, bioactive polyunsaturated fatty acids may increase oxidative stress (Frohnert et al., 2011). In rats, high-fat (HF) feeding typically increases plasma cholesterol, TAG and NEFA although the response varies according to various experimental factors (Muralidhar et al., 2017), e.g. whether the rats have been fasted prior to blood sampling (Ikeda et al., 2014). Selective breeding of Sprague-Dawley rats, of which around $50 \%$ are resistant to diet-induced obesity, has created obese prone rats (Levin et al., 1997). When fed a HF compared to a regular chow diet, obese prone rats become increasingly obese from day 35, develop insulin resistance from day 60, and hyperlipidemia from day 30-60 (Madsen et al., 2010).

It has been reported that diet per se does not seem to alter fatty acid oxidation (Heden et al., 2014). This may be due to protection by antioxidants, such as vitamin C (vitC), which has been shown to play a role as a cofactor in many metabolic processes and in quenching of otherwise harmful free radicals (Tveden-Nyborg and Lykkesfeldt, 2013). Chronic vitC deficiency in humans is associated with type 2 diabetes (Ford et al., 2003). In guinea pigs, HF compared to LF feeding reduced plasma vitC (Frikke-Schmidt et al., 2011). However, in contrast to humans and guinea pigs, rats produce vitC endogenously in the liver thereby allowing a homeostatic control independent of dietary restrictions. HF diet induces oxidative stress in rats (Noeman et al., 2011), yet the interaction between $\mathrm{HF}$ and endogenous vitC homeostasis in rats has not been studied in detail. Moreover, data on the effect of vitC supplementation to alleviate HF-induced obesity in rats are conflicting (Boqué et al., 2009; Picklo and Newman, 2015).

In the present study, we hypothesized that vitC production and mobilization to plasma is increased as in the early phase of a HF feeding of obese prone rats. 
The study was approved by the National Committee for Animal Experimentation, Ministry of Environment and Food, Copenhagen, Denmark (License Number: 2008/561-1537) according to the European Union Directive 2010/63/EU. After two weeks of acclimatization with free access to food and water in our AAALAC accredited facility (temperature at $21-22^{\circ} \mathrm{C}$, relative humidity at $55 \% \pm 10 \%$ and lights off from 6 pm to $6 \mathrm{am}), 15$ male six weeks old Crl:OP(CD) rats (Charles River, Kingston, NY, USA) were randomly divided into two groups (two or three per cage) receiving a HF (D12492; https://www.researchdiets.com/formulas/d12492; sucrose 9.4\%) or a LF diet (D12450B; https://www.researchdiets.com/formulas/d12450b; sucrose 33.5\%) free of vitC (Research Diets Inc., New Brunswick, NJ, USA). Body weight and accumulated food intake was recorded weekly and bi-weekly, respectively. After four weeks of dietary intervention, an oral glucose tolerance test (2 $\mathrm{mg}$ glucose/g body weight) was performed after 10 hours overnight fast with blood glucose measurements before dosing and after 30, 60, 90, and 120 minutes (Accu-Chek Aviva Glucometer; Hermedico, Copenhagen, Denmark). After additionally two weeks (week 6 of intervention), overnight fasted (10 hours) rats were anesthetised with isoflurane (Baxter, Søborg, Denmark), had blood collected from the periorbital plexus in heparin-coated microtubes, and were euthanized by cervical dislocation. Blood was centrifuged immediately. For ascorbic acid analyses, plasma was stabilized with an equal volume of cold $(10 \%(\mathrm{v} / \mathrm{v}))$ meta-phosphoric acid containing $2 \mathrm{mmol} / \mathrm{L}$ of EDTA, and mixed thoroughly and centrifuged. For analysis of glucose, cholesterol, NEFA and TAG on a Cobas Mira Plus (Roche Diagnostics, Hvidovre, Denmark) using reagents from Horiba ABX (Montpellier Cedex 4, France) and insulin by ELISA (Mercodia, Uppsala, Sweden) plasma was kept on dry ice until storage at $-80^{\circ} \mathrm{C}$. VitC was analyzed as previously described (Lykkesfeldt, 2007). Gulonolactone oxidase activity, i.e. the rate 
limiting enzyme in the biosynthesis of vitC, was assessed using liver homogenate as described elsewhere (Lykkesfeldt et al., 1998). Experimental groups were compared by unpaired t-test (significance level $\mathrm{P}<0.05$ ), and when relevant, data were logarithmically transformed to fit a normal distribution (Prism 5.02 (GraphPad Software Inc., San Diego, CA, USA) and SAS Analyst 9.2 (SAS Institute Inc., Cary, NC, USA)).

HF compared to LF diet significantly increased vitC concentration in plasma $(\mathrm{P}<0.001$; Figure 1A) and liver $(\mathrm{P}<0.01)$ (Figure 1B), while vitC biosynthesis, assessed by hepatic gulonolactone oxidase activity was unaffected (Figure 1C), indicating that a higher steady state concentration had been established with a vitC level adequate for supplying the systemic needs. This is in accordance with a previous study in mice, in which a HF diet significantly increased plasma concentrations of vitC compared with a control diet low in fat (Tranberg et al., 2014). However, in these mice hepatic de novo biosynthesis of vitC was upregulated as measured by gulonolactone oxidase activity, and liver vitC was reduced by HF feeding compared with low-fat feeding (Tranberg et al., 2014). Whether these differences in liver vitC status are general between rats and mice, a result of the selective breeding of the obese prone rats, or merely an effect of the respective time windows that the results represent are not known. In an earlier study, we compared intestinal and liver recycling capacity between guinea pigs, rats and mice and although lower than guinea pigs, rats and mice showed similar capacities to recycle vitC in both tissues (Frikke-Schmidt et al, 2016). Although this was not tested in HF animals, the results may indicate that differences in recycling are not responsible for the differential pattern between mice and rats. Beside changes in recycling capacity, differences in vitC clearance may also explain the effect of HF feeding. However, as neither recycling nor urinary vitC was assessed in the present study, we cannot discriminate between the se possible mechanisms leading to the apparently increased vitC homeostasis in $\mathrm{HF}$ 
animals. HF diet has previously been shown to increase weight gain after only ten days in obese prone rats (Ricci and Levin, 2003). In the present study, HF diet did not result in a significantly higher body weight (Figure 1D) or changes in glucose and insulin parameters (Table 1), and the effect of HF was mostly observed in the epididymal fat $(\mathrm{P}<0.05$, Figure 1E). This is not surprising, as ten weeks of HF compared to LF diet in rats is known to result in a 35-40\% increase in total body fat, while only in a $10 \%$ weight gain (Woods et al., 2003) or even less (Boozer et al., 1995). We did note a tendency towards accumulated energy intake in $\mathrm{HF}$ fed compared to $\mathrm{LF}$ fed rats $(\mathrm{P}=$ 0.08, Table 1), i.e. if the experiment had continued for a longer time a higher body weight might have been observed.

Although fasting plasma total cholesterol was unaffected (Figure 1F), fasting plasma triacylglycerol $(\mathrm{P}<0.01) \quad$ (Figure $1 \mathrm{G})$ and NEFA $(\mathrm{P}<0.001) \quad($ Figure 1H) were significantly decreased by HF feeding, which indicates induction of an increased lipid metabolization. In longer studies, HF diet has elevated plasma cholesterol (An et al., 2013; Madsen et al., 2010) and increased TAG may be observed already after 1-2 months of HF feeding (Madsen et al., 2010). Our negative observations may be explained by differences in LF diets, as macronutrient types and combinations are important for the response to development of obesity in rats (Muralidhar et al., 2017). High-sucrose diets, such as our LF diet, have been shown to increase TAG in Sprague Dawley rats (Pagliassotti et al., 2000). The rise in NEFA and TAG has been confirmed by another rat study using the same diets (De La Monte et al., 2009), while the two parameters were unaffected in a study in mice (Tranberg et al., 2013).

In conclusion, six weeks of HF feeding in obese prone rats increased plasma and liver vitC seemingly without hepatic de novo biosynthesis, which may help to protect the host in this early phase from increased body weight and decreased glucose tolerance. 
However, as vitC clearance or recycling was not assessed in the present study, the exact mechanisms underlying this increase remains to be established.

\section{Acknowledgements}

Annie Bjergby Kristensen is thanked for her skilled technical assistance. This study was supported in part by the Danish Agency for Science, Technology and Innovation (Grant No. 2101-07-0094). The study sponsor was not involved in the study design, in the collection, analysis and interpretation of data; in the writing of the manuscript; or in the decision to submit the manuscript for publication.

\section{Declarations of interest:}

None.

\section{References}

An, Y., Xu, W., Li, H., Lei, H., Zhang, L., Hao, F., Duan, Y., Yan, X., Zhao, Y., Wu, J., Wang, Y., Tang, H., 2013. High-fat diet induces dynamic metabolic alterations in multiple biological matrices of rats. J. Proteome Res. 12, 3755-3768. https://doi.org/10.1021/pr400398b

Boden, G., 2011. Obesity, insulin resistance and free fatty acids. Curr. Opin. Endocrinol. Diabetes Obes. 18, 139-143. https://doi.org/10.1097/MED.0b013e3283444b09

Boozer, C.N., Schoenbach, C., Atkinson, R.L., 1995. Dietary fat and adiposity: a doseresponse relationship in adult male rats fed isocalorically. Am. J. Physiol. 268, E546-50. https://doi.org/https://doi.org/10.1152/ajpendo.1995.268.4.E546 
Boqué, N., Campión, J., Milagro, F.I., Moreno-Aliaga, M.-J., Martinez, J.A., 2009.

Some cyclin-dependent kinase inhibitors-related genes are regulated by vitamin $\mathrm{C}$ in a model of diet-induced obesity. Biol. Pharm. Bull. 32, 1462-1468. https://doi.org/10.1248/bpb.32.1462

De La Monte, S.M., Tong, M., Lawton, M., Longato, L., 2009. Nitrosamine exposure exacerbates high fat diet-mediated type 2 diabetes mellitus, non-alcoholic steatohepatitis, and neurodegeneration with cognitive impairment. Mol. Neurodegener. 4. https://doi.org/10.1186/1750-1326-4-54

Ford, E.S., Mokdad, A.H., Giles, W.H., Brown, D.W., 2003. The metabolic syndrome and antioxidant concentrations: Findings from the Third National Health and Nutrition Examination Survey. Diabetes 52, 2346-2352. https://doi.org/10.2337/diabetes.52.9.2346

Frikke-Schmidt, H., Tveden-Nyborg, P., Birck, M.M., Lykkesfeldt, J., 2011. High dietary fat and cholesterol exacerbates chronic vitamin $\mathrm{C}$ deficiency in guinea pigs. Br. J. Nutr. 105, 54-61. https://doi.org/10.1017/S0007114510003077

Frikke-Schmidt, H., Tveden-Nyborg, P., Lykkesfeldt, J., 2016. L-dehydroascorbic acid can substitute 1 -ascorbic acid as dietary vitamin $\mathrm{C}$ source in guinea pigs. Redox Biol. 7, 8-13. https://doi.org/10.1016/j.redox.2015.11.003

Frohnert, B.I., Sinaiko, A.R., Serrot, F.J., Foncea, R.E., Moran, A., Ikramuddin, S., Choudry, U., Bernlohr, D.A., 2011. Increased adipose protein carbonylation in human obesity. Obesity 19, 1735-1741. https://doi.org/10.1038/oby.2011.115

Heden, T.D., Morris, E.M., Kearney, M.L., Liu, T.-W., Park, Y., Kanaley, J.A., Thyfault, J.P., 2014. Differential effects of low-fat and high-fat diets on fed-state 
hepatic triacylglycerol secretion, hepatic fatty acid profiles, and DGAT-1 protein expression in obese-prone Sprague-Dawley rats. Appl. Physiol. Nutr. Metab. 39, 472-479. https://doi.org/10.1139/apnm-2013-0410

Ikeda, I., Metoki, K., Yamahira, T., Kato, M., Inoue, N., Nagao, K., Yanagita, T., Shirakawa, H., Komai, M., 2014. Impact of fasting time on hepatic lipid metabolism in nutritional animal studies. Biosci. Biotechnol. Biochem. 78, 15841591. https://doi.org/10.1080/09168451.2014.923297

Levin, B.E., Dunn-Meynell, A., Balkan, B., Keesey, R.E., 1997. Selective breeding for diet-induced obesity and resistance in Sprague-Dawley rats. Am. J. Physiol. 273,

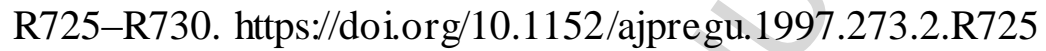

Lykkesfeldt, J., 2007. Ascorbate and dehydroascorbic acid as reliable biomarkers of oxidative stress: Analytical reproducibility and long-term stability of plasma samples subjected to acidic deproteinization. Cancer Epidemiol. Biomarkers Prev. 16, 2513-2516. https://doi.org/10.1158/1055-9965.EPI-07-0639

Lykkesfeldt, J., Hagen, T.M., Vinarsky, V., Ames, B.N., 1998. Age-associated decline in ascorbic acid concentration, recycling, and biosynthesis in rat hepatocytes-reversal with (R)-alpha-lipoic acid supplementation. FASEB J. 12, 1183-1189.

Madsen, A.N., Hansen, G., Paulsen, S.J., Lykkegaard, K., Tang-Christensen, M., Hansen, H.S., Levin, B.E., Larsen, P.J., Knudsen, L.B., Fosgerau, K., Vrang, N., 2010. Long-term characterization of the diet-induced obese and diet-resistant rat model: A polygenetic rat model mimicking the human obesity syndrome. J. Endocrinol. 206, 287-296. https://doi.org/10.1677/JOE-10-0004

Muralidhar, M.N., Prasad, S.M.V.., Battula, K.K., Giridharan, N.V., Kalashikam, R.R., 
2017. Differential response of rat strains to obesogenic diets underlines the importance of genetic makeup of an individual towards obesity. Sci. Rep. 7. https://doi.org/10.1038/s41598-017-09149-6

Noeman, S.A., Hamooda, H.E., Baalash, A.A., 2011. Biochemical Study of Oxidative Stress Markers in the Liver, Kidney and Heart of High Fat Diet Induced Obesity in Rats. Diabetol. Metab. Syndr. 3, 17. https://doi.org/10.1186/1758-5996-3-17

Pagliassotti, M.J., Gayles, E.C., Podolin, D. a, Wei, Y., Morin, C.L., 2000.

Developmental stage modifies diet-induced peripheral insulin resistance in rats. Am. J. Physiol. Regul. Integr. Comp. Physiol. 278, R66-R73.

Picklo, M.J., Newman, J.W., 2015. Antioxidant supplementation and obesity have independent effects on hepatic oxylipin profiles in insulin-resistant, obesity-prone rats. Free Radic. Biol. Med. 89, 182-191.

https://doi.org/10.1016/j. freeradbiomed.2015.07.152

Ricci, M.R., Levin, B.E., 2003. Ontogeny of diet-induced obesity in selectively bred Sprague-Dawley rats. Am. J. Physiol. - Regul. Integr. Comp. Physiol. 285, R610R618. https://doi.org/10.1152/ajpregu.00235.2003

Tranberg, B., Hansen, A.K., Lykkesfeldt, J., 2014. High-fat feeding increases hepatic vitamin C synthesis and its circulatory mobilization in mice. Eur. J. Nutr. 53. https://doi.org/10.1007/s00394-014-0694-z

Tranberg, B., Hellgren, L.I., Lykkesfeldt, J., Sejrsen, K., Jeamet, A., Rune, I., Ellekilde, M., Nielsen, D.S., Hansen, A.K., 2013. Whey Protein Reduces Early Life Weight Gain in Mice Fed a High-Fat Diet. PLoS One 8. https://doi.org/10.1371/journal.pone.0071439 
Tveden-Nyborg, P., Lykkesfeldt, J., 2013. Does Vitamin C Deficiency Increase Lifestyle-Associated Vascular Disease Progression? Evidence Based on Experimental and Clinical Studies. Antioxid. Redox Signal. 19, 2084-2104. https://doi.org/10.1089/ars.2013.5382

Woods, S.C., Seeley, R.J., Rushing, P. a, D’Alessio, D., Tso, P., 2003. A controlled high-fat diet induces an obese syndrome in rats. J. Nutr. 133, 1081-1087. 
Figure 1. Vitamin $\mathrm{C}$ analyses, body weight and lipid profiles in obese prone rats on high-fat (HF) or low-fat (LF) diet.

Plasma (A) and liver (B) vitamin C concentrations were significantly increased by HF while hepatic biosynthesis (C), assessed as gulonolactone oxidase activity, was similar between HF and LF. Body weight did not differ between mice fed high-or low fat diets (D) while epididymal fat was significantly increased by HF (E). Total plasma cholesterol was unaffected by diet (F). LF significantly increased triacylglycerol (G) and non-esterified fatty acids $(\mathrm{H})$.

$* \mathrm{P}<0.05, * * \mathrm{P}<0.01, * * * \mathrm{P}<0.001$

Table 1. Metabolic characteristics of Obese Prone rats after six weeks of high- or low fat diet feeding.

\begin{tabular}{lll} 
& Low-fat diet (n) & High-fat diet (n) \\
\hline Body weight gain (g/cage/animal) & $198.1 \pm 10.6(3)$ & $208.3 \pm 6.3(4)$ \\
Energy intake $(\mathrm{kJ} /$ cage/animal) & $14432 \pm 866(3)$ & $15737 \pm 736(4)$ \\
Feed efficiency $(\mathrm{mg} / \mathrm{kJ})$ & $13.7 \pm 0.4(3)$ & $13.2 \pm 0.5(4)$ \\
AUC OGTT & $943 \pm 120(3)$ & $971 \pm 68(5)$ \\
Glucose $(\mathrm{mM})^{\mathrm{b}}$ & $5.0 \pm 0.2(7)$ & $5.2 \pm 0.7(8)$ \\
Glucose $(\mathrm{mM})^{\mathrm{c}}$ & $7.7 \pm 0.7(7)$ & $8.2 \pm 0.8(8)$ \\
Insulin $(\mathrm{pM})^{\mathrm{c}}$ & $481.0 \pm 356.9(7)$ & $198.4 \pm 92.2(8)$ \\
QUICKI & $0.26 \pm 0.029(5)$ & $0.28 \pm 0.026(5)$ \\
\hline Data are shown as mean \pm 1 standard deviation. No significant dietary effects were \\
observed. Values for glucose and insulin were logarithmically & transformed before \\
statistical analyses.
\end{tabular}


${ }^{a}$ Feed efficiency was calculated as energy intake at cage level $[\mathrm{kJ}] /$ total weight gain of rats in the cage $[\mathrm{mg}]$

b The oral glucose tolerance test was conducted after four weeks of dietary intervention; AUC: area under the curve calculated by the trapezoidal method.

${ }^{\mathrm{b}}$ Based on plasma from anesthetized animals; QUICKI: Quantitative Insulin Sensitivity Check Index calculated by the equation: $1 /(\log$ insulin $[\mu \mathrm{U} / \mathrm{ml}]+\log$ glucose $[\mathrm{mg} / \mathrm{dl}])$.

Highlights

- Six weeks of high-fat feeding increases vitamin C in both liver and plasma of obese prone rats, which is in accordance with observations in mice

- This is not accompanied by an increased vitamin C biosynthesis, which is in contrast to observations in mice

- Glucose and insulin sensitivity is unaffected at this stage 


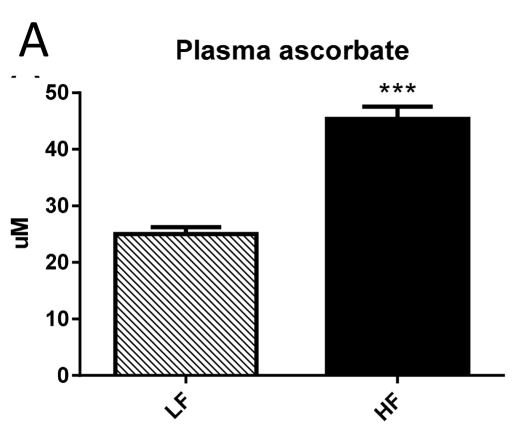

B

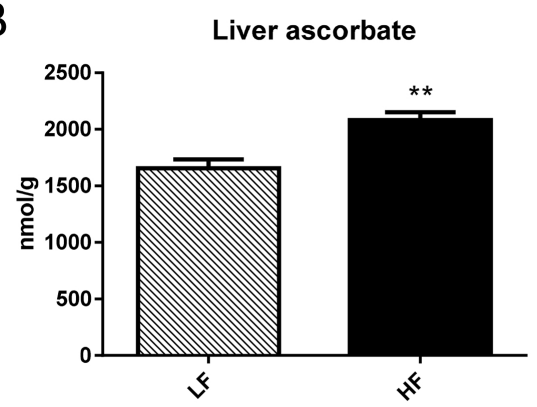

C Gulonolactone oxidase activity

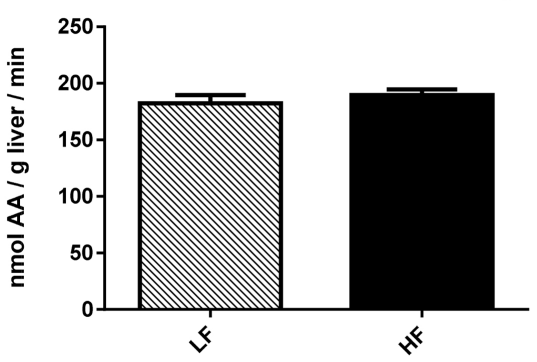

D

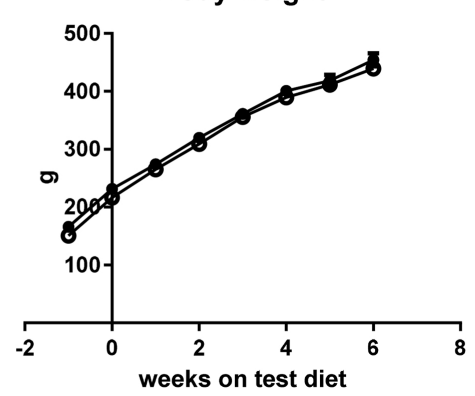

E

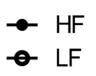

Epididymal fat

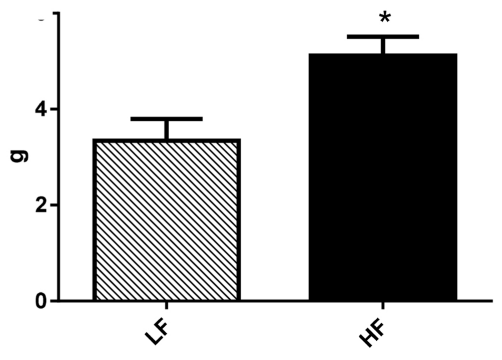

$\mathrm{F}$

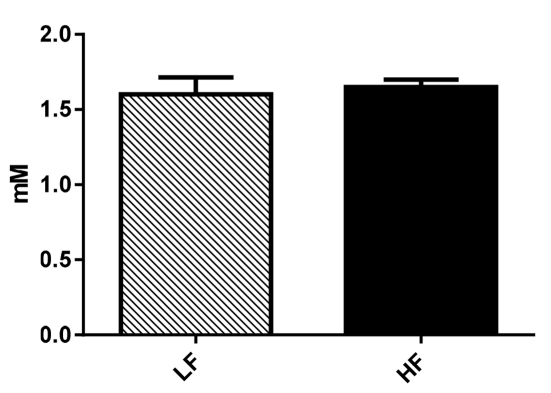

G

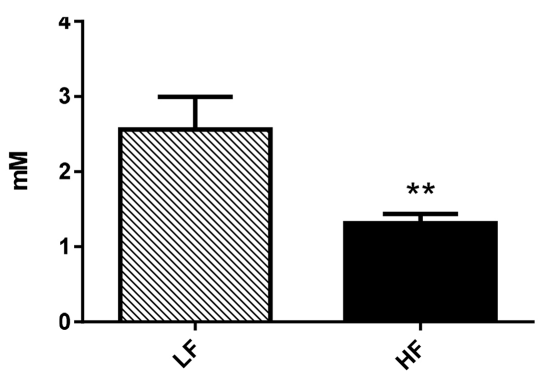

$\mathrm{H}$

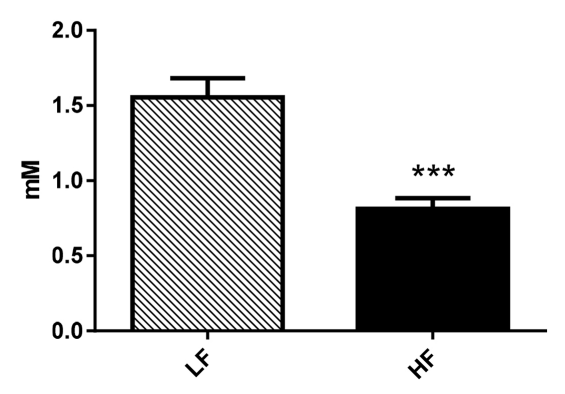

Figure 1 